\title{
Effect of oleuropein and peracetic acid on suspended cells and mono-species biofilms formed by Staphylococcus aureus and Escherichia coli
}

\author{
Laura CC Dominciano ${ }^{1}$, Sarah HI Lee ${ }^{1}$, Jéssica M Santello ${ }^{1}$, Elaine CP De Martinis ${ }^{2}$, Carlos H Corassin ${ }^{1}$ and Carlos AF Oliveira $^{1 *}$ \\ ${ }^{1}$ Department of Food Engineering, School of Animal Science and Food Engineering, University of São Paulo, Av. Duque de Caxias Norte, 225, CEP 13635-900, \\ Pirassununga, SP, Brazil \\ ${ }^{2}$ College of Pharmaceutical Sciences at Ribeirão Preto, University of São Paulo, CEP 14040-903, Ribeirão Preto, SP, Brazil
}

\begin{abstract}
This preliminary study evaluated the efficacy of oleuropein (OLE), a phenolic compound extracted from olive leaves, alone or in combination with peracetic acid (PAA) to inactivate Staphylococcus aureus (ATCC 25923) and Escherichia coli (ATCC 25922) in suspension and in mono-species biofilms. OLE (4.0 mg mL ${ }^{-1}$ ) alone exhibited mild antimicrobial activity on planktonic cells of $S$. aureus or $E$. coli, although no effect was observed on their biofilms formed on polystyrene microplates or stainless steel. PAA (2.0\%) reduced nearly $63 \%$ and $79 \%$ of adherent cells of $S$. aureus and E. coli, respectively. The combination of OLE with PAA slightly increased the inactivation of planktonic cells of both bacterial species and their biofilms on stainless steel, and reduced $(P<0.05) S$. aureus biofilms on polystyrene microplates. Results indicate a potential for using OLE as an additive to enhance the antimicrobial effect of PAA against biofilms formed by $S$. aureus.
\end{abstract}

\section{Introduction}

Biofilms are communities of sessile microorganisms in which primary colonizers adhere to a surface containing proteins or organic compounds and form micro colonies that synthesize extracellular matrix components that serve as substrate for adherence of other microorganisms [1]. Several pathogenic species including Staphylococcus aureus and Escherichia coli are known to form biofilms on different surfaces, especially in the food industry [2] and health-care environments [3]. Biofilms provide conditions for proliferation and persistence of pathogens and spoilage bacteria, which can also lead to increased bacterial resistance to sanitizing procedures [4].

Peracetic acid (PAA) is the active compound in many commercial sanitizers used at concentrations between 2 and $15 \%$ for disinfection of equipment and utensils in the food industry, agricultural premises and medical facilities [5]. Although several reports have demonstrated that PAA was effective in removing adhered $S$. aureus cells in-vitro $[5,6]$, it only partially reduced biofilms formed by E. coli O157:H7 [7]. Previous studies have indicated that oleuropein (OLE), a phenolic compound extracted from olive leaves, was effective against planktonic cells of several pathogens [8,9]. Dominciano et al. [10] observed that OLE alone in solution at $4.0 \mathrm{mg} \mathrm{mL}^{-1}$ had no effect on Listeria monocytogenes biofilms, but the combination of OLE with PAA resulted in greater inactivation of L. monocytogenes cells in biofilms. The aim of this study was to conduct a preliminary evaluation of the antimicrobial activity of OLE and PAA, alone or in combination, on S. aureus and E. coli cells in suspension and in mono-species biofilms formed on surfaces of polystyrene microplates and stainless steel.

\section{Material and methods}

\section{Bacterial strains}

S. aureus (ATCC 25923) and E. coli (ATCC 25922) strains were suspended in Brain Heart Infusion broth (BHI) (Merck, Germany) with $15 \%(\mathrm{v} / \mathrm{v})$ glycerol (Synth, Brazil) to form stock suspensions of each strain and were stored at $-80^{\circ} \mathrm{C}$. The bacterial working suspensions were prepared by adding $15 \mu \mathrm{L}$ of each stock suspension to $5 \mathrm{~mL}$ of BHI. After incubation at $30^{\circ} \mathrm{C}$ for $24 \mathrm{~h}$, the tubes were vortexed and diluted to 0.5 on the McFarland scale (nearly $10^{8}$ cells $\mathrm{mL}^{-1}$ ).

\section{Sensitivity of bacterial cells to oleuropein and peracetic acid}

OLE (purity: $>80 \%$ ) was purchased from Sigma-Aldrich (Saint Louis, MO) and diluted in sterilized water to prepare a working solution containing $4.0 \mathrm{mg} \mathrm{mL}^{-1}$, as described by Dominciano et al. [10]. A commercially available solution of PAA (Dinamica, São Paulo, Brazil) containing $2.0 \%(\mathrm{v} / \mathrm{v})$ was used in the experiment, which is the minimum PAA concentration commonly used for disinfection of equipment and utensils in the food industry [5]. The sensitivity of $E$. coli and $S$. aureus cells to OLE and PAA, alone or in combination, was assessed by agar disk diffusion using a modification of the National Committee for Clinical Laboratory Standards [11]. The bacterial working suspension was applied to Petri dish plates containing Mueller-Hinton Agar (Sigma-Aldrich ${ }^{\circledR}$ ) in triplicate. Sterilized filter paper discs $(6 \mathrm{~mm})$ were soaked in individual solutions containing OLE $\left(4.0 \mathrm{mg} \mathrm{mL}^{-1}\right)$, PAA $(2.0 \%, \mathrm{v} / \mathrm{v})$, or OLE + PAA $\left(4.0 \mathrm{mg} \mathrm{mL}^{-1}\right.$, and $2.0 \%, \mathrm{v} / \mathrm{v}$ ) for $1 \mathrm{~min}$. The disks were placed in the center of the prepared

Correspondence to: Carlos Augusto Fernandes de Oliveira, Departamento de Engenharia de Alimentos Faculdade de Zootecnia e Engenharia de Alimentos, Universidade de São Paulo, Av. Duque de Caxias Norte, 225-Campus, da USP, CEP 13635-900, Pirassununga/SP, Brazil; Tel: 19-3565-4173; Fax: 19-3565-4284; E-mail: carlosaf@usp.br

Keywords: oleuropein, peracetic acid, S. aureus, E. coli

Received: May 08, 2016; Accepted: May 26, 2016; Published: May 30, 2016 
Petri plates and incubated at $37^{\circ} \mathrm{C}$ for $48 \mathrm{~h}$. The diameters of inhibitory zones (IZ) were measured with a caliper rule and results were expressed for each sanitizer tested according to National Committee for Clinical Laboratory Standards [11]: resistant (R), when no inhibition zone was found beyond the disk diameter $(6 \mathrm{~mm})$, intermediate $(\mathrm{I})$, with $\mathrm{IZ}=6.1$ to $10 \mathrm{~mm}$, or sensitive (S), with IZ > $10 \mathrm{~mm}$.

\section{Efficacy of oleuropein and peracetic acid on biofilms on polystyrene microplate}

The mono-species biofilms were prepared following the method of Srey et al. [12]. An aliquot of $250 \mu \mathrm{L}$ of each bacterial suspension in BHI was pipetted in triplicate into 96-well, flat bottomed polystyrene microtiter plates (TPP, Switzerland). The microtiter plate was incubated at $37^{\circ} \mathrm{C}$ for $48 \mathrm{~h}$. The optical density (OD) of each well was measured at $600 \mathrm{~nm}$ using a microtiter plate reader (Labsystems, MultiSkan, USA). The planktonic cells and medium were then removed and each well was rinsed three times with $250 \mu \mathrm{L}$ of phosphate buffered saline (PBS). Aliquots of $250 \mu \mathrm{L}$ of OLE $\left(4.0 \mathrm{mg} \mathrm{mL}^{-1}\right)$, PAA $(2.0 \%, \mathrm{v} / \mathrm{v})$, or OLE + PAA $\left(4.0 \mathrm{mg} \mathrm{mL}^{-1}\right.$, and $\left.2.0 \%, \mathrm{v} / \mathrm{v}\right)$ were added to the wells. PBS was used instead of sanitizer in triplicate positive control wells (bacterial biofilm not subjected to any sanitizer challenge), and triplicate negative control wells were prepared with only BHI. The microtiter plates were kept at room temperature for 1 min., the sanitizer was removed and $250 \mu \mathrm{L}$ of sodium thiosulfate (Chemco, Brazil) was introduced into each well including the control wells and allowed to set for $5 \mathrm{~min}$. The wells were then rinsed three times with $250 \mu \mathrm{L}$ PBS and the biofilms were fixed with $250 \mu \mathrm{L}$ of methanol (Synth, Brazil) for $15 \mathrm{~min}$. After removing the methanol, the plate was dried for $30 \mathrm{~min}$ at room temperature and $250 \mu \mathrm{L}$ of crystal violet dye $0.1 \%$ (Synth, Brazil) was added to stain the biofilms for $15 \mathrm{~min}$. The dye was removed and the plate was rinsed with distilled water until the washing water was dye free. The plate was airdried for 2 hours and the stained bacterial cells were solubilized in 250 $\mu \mathrm{L}$ of acetic acid $(33 \%, \mathrm{v} / \mathrm{v})$ for $15 \mathrm{~min}$.

The OD of the dye solution was measured at $570 \mathrm{~nm}$. The effectiveness of biofilm removal by the sanitizers was compared using the biofilm formation index (BFI) calculated according to Equation 1 (Niu and Gilbert [13]), where $\mathrm{OD}_{570 \mathrm{~nm}}$ was obtained from the biofilm treated with sanitizer or from positive control wells (biofilm treated with PBS) after staining, ODC $_{570 \mathrm{~nm}}$ was obtained from negative control wells (BHI only treated with PBS) after staining, $\mathrm{OD}_{600 \mathrm{~nm}}$ was obtained from the non-stained, untreated (before challenge with sanitizer) or positive control wells, and $\mathrm{ODC}_{600 \mathrm{~nm}}$ was obtained from the nonstained, negative control wells.

$$
B F I=\frac{\left(O D_{570 n m}-O D C_{570 n m}\right)}{\left(O D_{600 \mathrm{~nm}}-O D C_{600 \mathrm{~nm}}\right)}
$$

BFI values were analyzed by one-way analysis of variance according to Gacula and Singh [14]. The means for treatments showing significant differences were compared using the Tukey test. Statistical significance was considered at $P<0.05$.

\section{Efficacy of oleuropein and peracetic acid on biofilms on stainless steel}

The production of biofilms on stainless steel followed the procedures of Chandra et al. [15] where sterilized stainless steel square coupons $(1.0 \times 1.0 \mathrm{~cm})$ were incubated at $37^{\circ} \mathrm{C}$ for $48 \mathrm{~h}$ in triplicate. After 24 $\mathrm{h}$ incubation, an additional $2 \mathrm{~mL}$ of BHI was added to each tube to renew the nutritious supply for biofilm formation [16]. The biofilms on stainless steel coupons were treated with individual solutions (2
$\mathrm{mL})$ containing OLE $\left(5.0 \mathrm{mg} \mathrm{mL}^{-1}\right), \mathrm{PAA}(2.0 \%$, v/v) or OLE + PAA $\left(5.0 \mathrm{mg} \mathrm{mL}^{-1}\right.$, and $\left.2.0 \%, \mathrm{v} / \mathrm{v}\right)$ for $1 \mathrm{~min}$. After treatment, the stainless steel coupons were removed from the tubes with sterile forceps, washed with PBS three times to remove the non-adhered cells, allowed to dry at room temperature, and finally placed into NUNC wells (Lab-Tek Chamber Slide System, USA).

The viability of surface-bound bacteria in mono-species biofilms after treatment with OLE and/or PAA was examined by adding $30 \mu \mathrm{L}$ of LIVE/DEAD ${ }^{\circ}$ Backlight kit (Molecular Probes, OR, USA) containing SYTO 9 and propidium iodide dyes directly onto the stainless steel coupons. After 10 minutes of incubation, the coupons were examined in a TCS SP5 ${ }^{\circ}$ confocal laser scanning (CLS) microscope (Leica Microsystems, Germany) for visualization of biofilms. An argon laser ( $488 \mathrm{~nm}$, fluorescent green) was used to observe cells stained with SYTO 9 , and a helium laser ( $543 \mathrm{~nm}$, fluorescent red) was used to observe cells stained with propidium iodide. The images were processed using LAS AF ${ }^{\circ}$ software (Leica Microsystems, Germany).

\section{Results}

The sensitivities of E. coli and S. aureus suspended cells to OLE and PAA, alone or in combination, using the disk diffusion method are presented in Table 1. Both bacterial species were sensitive to PAA (IZ $>10 \mathrm{~mm}$ ) according to the classification proposed by the National Committee for Clinical Laboratory Standards [11]. OLE alone also showed antimicrobial activity against the bacterial cells tested, although their sensitivities were classified as intermediate (IZ: $7.3 \pm 0.9$ and 10.0 $\pm 1.6 \mathrm{~mm}$ for $E$. coli and $S$. aureus, respectively). The combination of OLE and PAA slightly increased (nearly 1-2 mm) their individual IZ values for E. coli and S. aureus.

Table 2 presents the BFI values and percentage reductions of mono-species biofilms formed by E. coli and S. aureus after treatment with OLE and PAA alone or in combination. OLE alone had no effect

Table 1. Sensitivity of Staphylococcus aureus and Escherichia coli suspended cells to oleuropein (OLE, $4.0 \mathrm{mg} \mathrm{mL}^{-1}$ ) and peracetic acid (PAA, 2.0\%, v/v), alone or in combination, using the disk diffusion meth.od

\begin{tabular}{|c|c|c|c|c|}
\hline \multirow{2}{*}{ Compound } & \multicolumn{2}{|c|}{ Staphylococcus aureus } & \multicolumn{2}{c|}{ Escherichia coli } \\
\cline { 2 - 5 } & $\begin{array}{c}\text { Inhibition zone } \\
(\mathbf{m m})^{\mathbf{1}}\end{array}$ & Classification $^{\mathbf{2}}$ & $\begin{array}{c}\text { Inhibition zone } \\
(\mathbf{m m})^{\mathbf{1}}\end{array}$ & Classification $^{\mathbf{2}}$ \\
\hline OLE & $10.0 \pm 1.6$ & $\mathrm{I}$ & $7.3 \pm 0.9$ & $\mathrm{I}$ \\
\hline PAA & $10.3 \pm 0.5$ & $\mathrm{~S}$ & $11.3 \pm 2.4$ & $\mathrm{~S}$ \\
\hline PAA + OLE & $11.7 \pm 0.5$ & $\mathrm{~S}$ & $12.0 \pm 0.1$ & $\mathrm{~S}$ \\
\hline
\end{tabular}

${ }^{1}$ Results are reported as mean \pm standard deviation of triplicate assays ${ }^{2}$ Classification according to National Committee for Clinical Laboratory Standards (2003) Intermediate (I): Inhibition zone (IZ) $=6.1$ to $10 \mathrm{~mm}$; Sensitive (S): IZ $>10 \mathrm{~mm}$. Disk diameter $=6 \mathrm{~mm}$.

Table 2. Biofilm formation index (BFI) and percentage reduction of Escherichia coli and Staphylococcus aureus mono-species biofilms on polystyrene microplates, after treatment with oleuropein (OLE, $4.0 \mathrm{mg} \mathrm{mL}^{-1}$ ) and peracetic acid (PAA, 2.0\%, v/v) alone or in combination.

\begin{tabular}{|c|c|c|c|c|}
\hline \multirow{2}{*}{ Treatment } & \multicolumn{2}{|c|}{ Staphylococcus aureus } & \multicolumn{2}{c|}{ Escherichia coli } \\
\cline { 2 - 5 } & BFI $^{1}$ & Reduction $^{\mathbf{2}} \mathbf{( \% )}$ & BFI $^{\mathbf{1}}$ & Reduction $^{\mathbf{2}} \mathbf{( \% )}$ \\
\hline Control & $0.61 \pm 0.29^{\text {a }}$ & - & $0.55 \pm 0.09^{\text {a }}$ & - \\
\hline OLE & $0.69 \pm 0.14^{\text {a }}$ & 0 & $0.66 \pm 0.16^{\text {a }}$ & 0 \\
\hline PAA & $0.24 \pm 0.02^{\text {b }}$ & $63.5 \pm 1.7^{\text {b }}$ & $0.13 \pm 0.06^{\text {b }}$ & $79.1 \pm 2.1^{\text {a }}$ \\
\hline PAA + OLE & $0.11 \pm 0.08^{\text {c }}$ & $83.7 \pm 2.4^{\text {a }}$ & $0.10 \pm 0.01^{\text {b }}$ & $80.9 \pm 1.9^{\text {a }}$ \\
\hline
\end{tabular}

${ }^{1}$ Results are reported as mean \pm standard deviation of triplicate assays.

${ }^{2}$ Percentage calculated in relation to the control (biofilm treated with phosphate buffer solution).

${ }^{a-b}$ In the same column, means followed by different letters differ significantly $(\mathrm{P}<0.05)$. 
$(P>0.05)$ on mono-species biofilms formed by E. coli or S. aureus. Compared with controls (biofilms treated with PBS only), PAA alone reduced $(P<0.05)$ the BFI values of mono-species biofilms of $E$. coli and $S$. aureus, although the percentage reduction was higher for E. coli (nearly 79\%), when compared with S. aureus (nearly 63\%). Although the effects of PAA alone or in combination with OLE on E. coli biofilms were not different $(P>0.05)$, the BFI and reduction values for $S$. aureus treated with PAA + OLE were lower $(P<0.05)$ than the PAA alone, leading to nearly $84 \%$ reduction of the biofilm mass on polystyrene microplates.
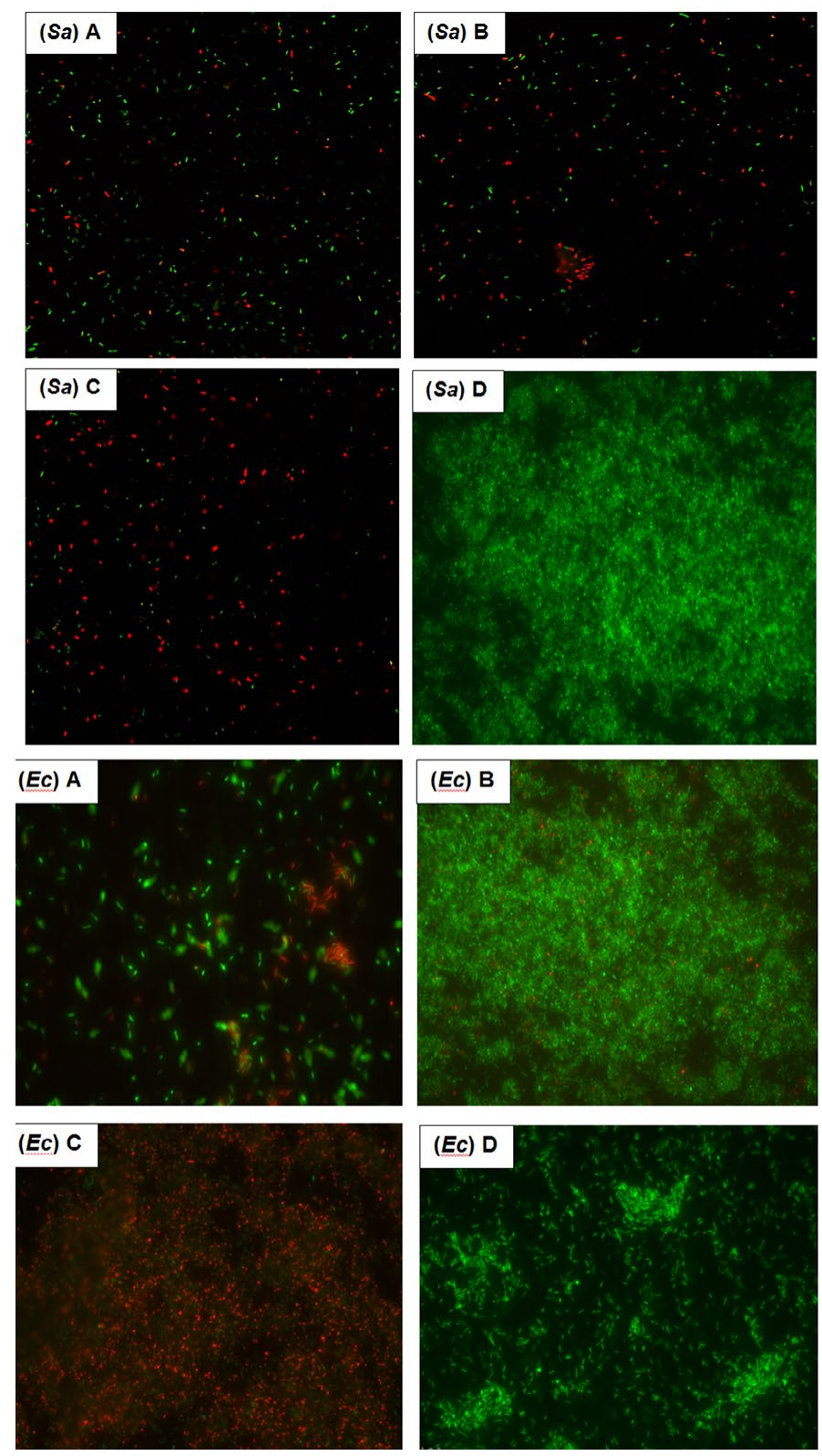

Figure 1. Confocal laser scanning micrographs of biofilms formed by Staphylococcus aureus ATCC 25923 ( $\mathrm{Sa}$ ) and Escherichia coli ATCC 25922 (Ec) on stainless steel surfaces for 48 hours at $37^{\circ} \mathrm{C}$, after treatment for 1 min. with A) peracetic acid $\left.(2.0 \%, v / v), B\right)$ oleuropein $\left(4.0 \mathrm{mg} \mathrm{mL}^{-1}\right)$ or C) peracetic acid + oleuropein $\left(4.0 \mathrm{mg} \mathrm{mL}^{-1}\right.$ and $2.0 \%$, v/v, respectively). Untreated (control) biofilm is shown in D. Biofilms were stained with bacterial viability kit LIVE/DEAD ${ }^{\circledR}$ BacLight (Molecular Probes, US), in which viable cells are fluorescent green (Syto 9) and non-viable cells are fluorescent red (propidium iodide). Images were captured with $10 \mathrm{x}$ ocular and $63 \mathrm{x}$ objective with oil immersion, and zoom of 2.5 Scale bar $=10 \mu \mathrm{m}$.
Figure 1 presents the CLS photomicrographs of mono-species biofilms formed by $S$. aureus and $E$. coli after contact with OLE alone or in combination with PAA. Biofilms treated with OLE alone had a predominance of live, green (Syto 9) colored cells (Figure 1SaA and $1 E c \mathrm{~A}$ ), indicating little effect on S. aureus and E. coli biofilms which was similar to the results found for mono-species biofilms on polystyrene microplates. PAA alone decreased the number of live, adherent cells of $S$. aureus (Figure $1 S a B$ ), but had only a mild effect on $E$. coli cells (Figure $1 E c \mathrm{~B}$ ) on stainless steel coupons. The combination of OLE and PAA lead to a higher inactivation of both $S$. aureus and E. coli cells (Figures $1 \mathrm{SaC}$ and $1 E c \mathrm{D}$, respectively).

\section{Discussion}

As expected, PAA was effective against E. coli and S. aureus suspended cells in the disk diffusion method. The intermediate inhibitory effect of OLE against the pathogens tested was consistent with previous studies describing antimicrobial activities of phenolic compounds of olive oil $[8,9]$. The main factors that could interfere with IZ values obtained in the disk diffusion method include the dispersion and emulsification properties of the tested compound in the agar [17]. Thus the hydrophobic nature of OLE could have prevented its uniform diffusion through the agar and decreased the IZ values when compared with PAA. The slight increase in the IZ values of the combination of OLE + PAA for E. coli and S. aureus indicates a mild additive effect, although the comparison of results obtained in this study with others is difficult as there is no previous report on the inhibitory effect of OLE in combination with PAA on the bacterial species evaluated.

The results for PAA effect on $S$. aureus biofilms on polystyrene microplates agree with those described by Marques [5] and VásquezSánchez [6]. The BFI value allows an estimation of the effect of sanitizers to remove the bacterial biofilm mass from a surface [12]. Therefore the greater reduction effect of PAA on E. coli biofilms was surprising since this species has a strong ability to adhere and form biofilms due to mobility properties of the bacterial cell such as flagella and lower generation time when compared with $S$. aureus [18]. The fact that PAA did not completely remove the biomass of monospecies biofilms from polystyrene microplates warrants concern about the occurrence of $E$. coli and $S$. aureus on surfaces of equipment and utensils even after contact with the sanitizer. The no-effect of OLE against mono-species biofilms formed by E. coli or S. aureus in the present study were different from those described by Nostro et al. [19], who observed a complete elimination of biofilm formed by $S$. aureus after treatment with essential oils extracted from oregano. However, data reported in this study and those previously mentioned works are not fully comparable because they used olive extracts that may contain other active phenolic compounds, instead of the isolated OLE. The lower BFI and reduction values for S. aureus treated with PAA + OLE, compared with PAA alone, corroborates the additive effect of PAA and OLE on planktonic cells of $S$. aureus using the disk diffusion method, and also agrees with a previous report describing increased inactivation of Listeria monocytogenes biofilms by OLE and PAA [10].

On stainless steel, the combination of OLE and PAA led to a higher inactivation of both $S$. aureus and E. coli cells. The physical-chemical properties of the surfaces used in the food industry can influence bacterial adhesion, since they readily adhere to hydrophobic surfaces such as polystyrene and stainless steel, as compared to hydrophilic materials (e.g., glass) [3]. S. aureus had a higher capacity to form biofilms on polystyrene surfaces than stainless steel, suggesting that hydrophobicity is an important factor in the formation of such 
biofilms [20]. However, Lee et al. [21] did not observe any variation in the biofilm formation ability of $S$. aureus on surfaces of polystyrene or stainless steel, which is in agreement with data reported in this study. Biofilms are constituted by sessile cells, single or multispecies adhered to a substrate, in which the microorganisms exhibit distinct phenotypes, metabolism, physiology and gene transcription [3]. The mechanisms of antimicrobial activity of OLE are not completely understood. Phenolic compounds have the ability to increase the permeability of cell membranes thus facilitating their rupture [22]. Previous studies have shown that OLE interacts with phosphatidylglycerol at the surface of the bacterial cell membrane, which changes the cytoplasmic membrane leading to the disruption of the cell envelope [23]. Therefore, these effects may have contributed to the greater antimicrobial activity of PAA combined with OLE.

In conclusion, the combination of OLE with PAA increased the inactivation of $S$. aureus mono-species biofilms on polystyrene microplates and stainless steel. These preliminary results indicate a potential for using OLE as additive to enhance the antimicrobial effect of PAA on biofilms formed by $S$. aureus. Further studies are necessary to understand the mechanisms of action of OLE in combination with commercial chemical sanitizers.

\section{Acknowledgements}

The authors thank the Conselho Nacional de Desenvolvimento Científico e Tecnológico (CNPq, Grant 309348/2013-7), for financial support. They are also grateful to M.Sc. Vanessa M. de Souza (FCFRP/ USP) for her technical assistance during sample preparation for CLS microscopy, and to Ms. Elizabete R. Milani (FMRP/SP) for running the CLS microscopy analyses.

\section{Conflict of interest}

Authors declare no conflict of interest.

\section{References}

1. Cappitelli F, Polo A, Villa F (2014) Biofilm formation in food processing environments is still poorly understood and controlled. Food Eng Rev 6: 29-42.

2. Bridier A, Sanchez-Vizuete P, Guilbaud M, Piard JC, Naïtali M (2015) Biofilmassociated persistence of food-borne pathogens. Food Microbiol 45: 167-78.

3. Donlan RM, Costerton JM (2002) Biofilms: survival mechanisms on clinically relevant microorganisms. Clinical Microbiol Review 15: 167-93.

4. Tiba MR, Nogueira GP, Leite DS (2009) Study on virulence factors associated with biofilm formation and phylogenetic groupings in Escherichia coli strains isolated from patients with cystitis. Rev Soc Bras Med Trop 42: 58-62.

5. Marques SC, Rezende JGOS, Alves LAF, Silva BC, Alves E, et al. (2007) Formation of biofilms by Staphylococcus aureus on stainless steel and glass surfaces and its resistance to some selected chemical sanitizers. Brazilian J Microbiol 38: 538-43.

6. Vásquez-Sánchez D, Cabo ML, Ibusquiza PS, Rodrígues-Herrera JJ (2014) Biofilm- forming ability and resistance to industrial disinfectants of Staphylococcus aureus isolated from fishery products. Food Control 39: 8-16.

7. Simpson Beauchamp C, Dourou D, Geornaras I, Yoon Y, Scanga JA, et al. (2012) Transfer, attachment, and formation of biofilms by Escherichia coli O157:H7 on meatcontact surface materials. J Food Sci 77: M343-347. [Crossref]

8. Tripoli E, Giammanco M, Tabacchi G, Majo DD, Giammanco S (2005) The phenolic compounds of olive oil: structure, biological activity and beneficial effects on human health. Nutr Res Reviews 18: 98-112.

9. Pereira AP, Ferreira IC, Marcelino F, Valentão P, Andrade PB, et al. (2007) Phenolic compounds and antimicrobial activity of olive (Olea europaea L. Cv. Cobrançosa) leaves. Molecules 12: 1153-1162. [Crossref]

10. Dominciano LCC, Lee SHI, Rosim RE, Corassin CH, Oliveira CAF (2016) Effects of oleuropein and peracetic acid as sanitizing agents for inactivation of Listeria monocytogenes biofilms. The Open Conference Proceed J 7: 1-6.

11. National Committee for Clinical Laboratory Standards (2003) Methods for dilution antimicrobial susceptibility tests for bacateria that grow aerobically, $6^{\text {a }}$ edition; Approved Standard. NCCLS Document M7-A6. Wayne 23

12. Srey S, Young PS, Kabir JI, Se-Ra O, Noori H, et al. (2014) Evaluation of the removal and destruction effect of a chlorine and thiamine dilaurylsulfate combined treatment on L. monocytogenes biofilm. Foodborne Path and Dis 11: 658-63.

13. Niu C, Gilbert ES (2004) Colorimetric method for identifying plant essential oi components that affect biofilm formation and structure. Appl Environ Microbiol 70: 6951-6956. [Crossref]

14. Gacula JR, Singh J (1984) Statistical methods in food and consumer research Academic Press: Orlando.

15. Chandra J, Mukherjee PK, Ghannoum MA (2008) In vitro growth and analysis of Candida biofilms. Nat Protoc 3: 1909-1924. [Crossref]

16. Shanks RM, Donegan NP, Graber ML, Buckingham SE, Zegans ME, et al. (2005) Heparin stimulates Staphylococcus aureus biofilm formation. Infect Immun 73: 45964606. [Crossref]

17. Ríos JL, Recio MC (2005) Medicinal plants and antimicrobial activity. $J$ Ethnopharmacol 100: 80-84. [Crossref]

18. Pompermayer DMC, Gaylarde CC (2000) The influence of temperature on the adhesion of mixed cultures of Staphylococcus aureus and Escherichia coli to polypropylene. Food Microbiol 4: 361-365.

19. Nostro A, Sudano Roccaro A, Bisignano G, Marino A, Cannatelli MA, et al. (2007) Effects of oregano, carvacrol and thymol on Staphylococcus aureus and Staphylococcus epidermidis biofilms. J Med Microbiol 56: 519-523. [Crossref]

20. Pagedar A, Singh J, Batish VK (2010) Surface hydrophobicity, nutritional contents affect Staphylococcus aureus biofilms and temperature influences its survival in performed biofilms. J Basic Microbiol 50: S98-S106.

21. Lee SH, Mangolin BL, Gonçalves JL, Neeff DV, Silva MP, et al. (2014) Biofilmproducing ability of Staphylococcus aureus isolates from Brazilian dairy farms. J Dairy Sci 97: 1812-1816. [Crossref]

22. Taweechaisupapong S, Ngaonee P, Patsuk P, Pitiphat W, Khunkitti W (2012) Antibiofilm activity and post antifungal effect of lemongrass oil on clinical Candida dubliniensis isolate. South African J Botany 78: 37-43.

23. Casas-Sanchez J, Alsina MA, Herrlein MK, Mestres C (2007) Interaction between the antibacterial compound, oleuropein, and model membranes. Colloid Polym Sci 285 $1351-60$

Copyright: (C2016 Dominciano LCC. This is an open-access article distributed under the terms of the Creative Commons Attribution License, which permits unrestricted use, distribution, and reproduction in any medium, provided the original author and source are credited. 